\title{
La representación de las mujeres en el nuevo Museo Arqueológico Nacional: comenzando por la Prehistoria
}

\author{
The Representation of Women in the New National Archaeological \\ Museum: Beginning with Prehistory
}

\author{
$M^{a}$ Ángeles Querol \\ Departamento de Prehistoria. Facultad de Geografía e Historia \\ Universidad Complutense de Madrid \\ 28040 Madrid \\ maquerol@ghis.ucm.es \\ Francisca Hornos \\ Museo Provincial de Jaén \\ Paseo de la Estación 27 \\ 23008 Jaén. \\ francisca.hornos@gmail.com
}

Recibido: 16-06-2014

Aceptado: 14-11-2014

\begin{abstract}
RESUMEN
En la misma línea de trabajos anteriores, nos planteamos la necesidad de que en los museos arqueológicos se proceda con sumo cuidado a seleccionar el género de las personas que se representan en las escenas sociales, equilibrando tanto su número como sus actitudes, los trabajos que desempeñan, sus roles y su protagonismo. Analizamos asi la representación de las mujeres en las escenas, considerando como tal cualquier reproducción en la que aparezcan dos o más personas en interacción.

El trabajo realizado en la nueva exposición del MAN, que se refiere tan sólo a las salas de Prehistoria y Protohistoria, nos demuestra la existencia de un 25,1\% de mujeres en estas escenas, incluyendo en muchos casos protagonismo, participación en trabajos de construcción o minería y ocupación de primeros planos. Esto lo sitúa en la banda más alta de entre los museos hasta ahora estudiados.

El nuevo Museo Arqueológico Nacional ha dedicado seis años a reorganizarse y vestirse con nuevos ropajes, y ahora se nos presenta como un museo renovado pero al tiempo conservado en su esencia. Esa renovación ha incluido, en gran medida, un cuidado detallista en la representación de las mujeres en el pasado.
\end{abstract}

Palabras Clave: Arqueología feminista. Representación de mujeres. Educación en igualdad. Museos.

\begin{abstract}
As in previous works done, we feel the need that in archaeological museums the selection of the gender of the people who are represented in the social scenes should be done very carefully, balancing both the number and the attitudes, what they do, their roles and their significance. To this end, we have analyzed the representation of women in the museum scenes, considering as such, any reproduction in which two or more persons are interacting.

The work performed in the new exhibition at the National Archaeological Museum (MAN) of Madrid, regarding only to the rooms of Prehistory and Protohistory, show the presence of $25.1 \%$ of women in these scenes, including in many cases the participation in construction or mining works, and the presence of women occupying close-ups. This, places this museum in the highest positions including women's presence in the scenes, among all the museums studied until now. The new archaeological museum has taken six years to reorganize and reshape the collection, and is now presented as a renovated Museum but preserving at the same its essence. This renewal has included, to a great extent, a detailed care in the representation of women in the past.
\end{abstract}

KEY wORDs: Feminist archaeology. Representation of women. Equal education. Museums. 


\section{Introducción: Una historia remota sin mujeres}

Hace algo más de una década iniciamos una serie de trabajos destinados a analizar la representación de las mujeres en las escenas que decoran los museos arqueológicos o de historia, los libros de texto sobre historia en sus capítulos iniciales, y las exposiciones sobre los temas prehistóricos. Partimos de un principio básico: las imágenes entran por los ojos, sobre todo de las criaturas, mucho más que los carteles escritos, y esas imágenes se graban en el subconsciente como cualquier otro elemento educativo. ¿Qué es lo que nuestros museos, textos o exposiciones están enseñando sobre las sociedades del pasado desde el punto de vista feminista de la igualdad o el equilibrio? ¿Se trata de un tema consciente, pensado y discutido o se origina al azar?

Es esta una cuestión sobre la que ya hemos publicado con anterioridad, bien en soledad (Querol 2003, 2005 y 2006), ambas juntas (Querol y Hornos 2011) o con otras personas (Hornos y Rísquez 2000 y 2005; Querol y Triviño 2004), $\mathrm{y}$ en los sucesivos casos aclaramos que nuestro planteamiento es feminista: si el pasado sirve para comprendernos como seres humanos, la reconstrucción o la representación de ese pasado ha de ser sumamente cuidadosa y no asumir una pretendida inocencia que nunca existe; recordar también que los mensajes que emanan del mundo profesional y van hacia la sociedad por medio de los museos, "son tomados como ciertos por el público dado el contexto oficial en el que se encuentran" (Díaz Andreu 2005). Por lo tanto, defendemos con nuestros artículos la necesidad de transmitir mensajes sociales pensados, discutidos incluso y, sobre todo, conscientes. Trabajamos por la utopía de una educación en igualdad.

El eje central de nuestro tema, nuestro objetivo, no es que las representaciones nos muestren a ambos géneros haciendo las mismas tareas $u$ ocupando los mismos espacios, sino que exista un equilibrio numérico y espacial, simbólico y de actitudes, entre hombres y mujeres, aun realizando los trabajos que "tradicionalmente" se suponen propios de uno u otro sexo. En palabras de Soler Begoña (2008):

"el problema añadido viene cuando la caza es considerada la actividad económica "importante" y por tanto quienes la practican son los "importantes del grupo", mientras que las actividades vinculadas con el mantenimiento del grupo son consideradas "menores" y por ende quienes las practican también".

Las exposiciones de los museos arqueológicos centran su objetivo y definen su importancia por la naturaleza de los objetos que muestran, sobre los que nunca se permitirían el error de confundirse en la atribución "cultural" de un vaso o de una piedra tallada. No suele ocurrir lo mismo cuando lo que se presenta y representa son personas en acción, grupos sociales en dibujos, interactivos, videos, hologramas u otros sistemas más o menos modernos. Por lo general se discute, museográficamente, sobre el objeto que se ha de enseñar, el lugar que debe ocupar o la luz que debe tener, pero las decisiones sobre a quiénes representar, en qué actitudes o realizando qué labores, suelen dejarse en manos no especializadas en la reconstrucción de discursos sociales sobre el pasado, se toman como adornos, algo superficial y sin importancia que, ante todo, debe quedar "bonito". Las personas que se dedican a dibujar o a reproducir por cualquier medio, ante la ausencia de normas "científicas", acuden a actualismos en los que suponen que las mujeres del pasado -y aquí da igual si más o menos remoto- ocupaban los lugares y realizaban las tareas de la misma forma que nuestras campesinas del siglo XIX. Y nos presentan a las mujeres de rodillas, cocinando, cuidando criaturas, en espacios interiores, en actitudes de docilidad, nunca protagonizando escenas y casi siempre arrinconadas en esos sitios y roles a los que hoy se les da muy escasa importancia.

Y además, pocas. En un artículo publicado hace poco (Querol y Hornos 2011) analizamos la representación de las mujeres en cinco museos arqueológicos inaugurados todos ellos en el presente siglo: el de Almería, el de la Evolución Humana en Burgos y los de Bilbao, Alicante y Oviedo. El porcentaje de mujeres representadas en las escenas (llamamos escena a cualquier reproducción en la que aparezcan dos o más personas en interacción) era el siguiente:

\begin{tabular}{|l|c|c|}
\hline \multicolumn{1}{|c|}{ MUSEO } & $\begin{array}{c}\text { PERSONAS } \\
\text { RECONOCIBLES }\end{array}$ & \%MUJERES \\
\hline ALMERÍA & 265 & $33 \%$ \\
\hline BURGOS & 223 & $25,5 \%$ \\
\hline BILBAO & 183 & $20 \%$ \\
\hline
\end{tabular}




\begin{tabular}{|l|c|l|}
\hline ALICANTE & 700 & $13 \%$ \\
\hline OVIEDO & 278 & $12 \%$ \\
\hline TOTALES & 1649 & $23 \%$ \\
\hline
\end{tabular}

Aunque el resultado final no es demasiado favorecedor para nuestro objetivo, es interesante comparar estas cifras con las que obteníamos hace poco más de una década en el estudio de exposiciones y textos escolares sobre los orígenes humanos, que nunca superó el 15\% (ver Querol 2000 y 2001). Suponemos que no hace falta recordar que somos el $50 \%$ de las sociedades humanas.

Por lo que respecta al nuevo Museo Arqueológico Nacional, que a pesar de su vetusta edad nunca ha sido tan nuevo como ahora, gracias a la amabilidad de su director, Andrés Carretero, pudimos realizar este trabajo antes de su inauguración, en enero de $2014^{1}$.

Con casi $10.000 \mathrm{~m}^{2}$ de exposición permanente y unos tres kilómetros de recorrido, el naciente MAN ha abierto sus espacios a las nuevas tecnologías de la imagen y sin duda ha realizado un gran esfuerzo por adaptar su mensaje a los tiempos actuales. Este complejo proceso, que ha involucrado a las últimas dos direcciones y a un considerable número de personas internas y externas a la institución, se ha realizado entre los años 2008 y 2013 y ha sido detalladamente comentado en un artículo reciente de su propio director (Carretero 2012).

Así pues, el museo de los museos arqueológicos españoles ha entrado en el siglo XXI, pero sigue siendo el que fue porque sus colecciones son su fortaleza principal y este museo no puede atenerse a un discurso que no sea el tradicional, ya que sus objetos proceden de intervenciones más relacionadas con la anticuaria que con la nueva ciencia arqueológica. En un museo histórico es necesario exponer los conocimientos actuales, pero en éste además hay que contar las distintas etapas de adquisición de las colecciones, reflejando una visión lo más extendida posible en lo espacial y en lo temporal. En definitiva, el nuevo MAN se nos presenta como un museo renovado pero al tiempo conservado en su esencia.

Al encontrarnos con una exposición de tales dimensiones, decidimos centrar el análisis de la representación de las mujeres en las salas de Prehistoria y Protohistoria. Aun así, la escala resulta completamente diferente a la de los otros cinco museos estudiados: en el MAN se concentra lo mejor de la Arqueología de todas las regiones de nuestro país y los resultados que podíamos obtener tenían a priori una importancia básica por el carácter ejemplar de este tipo de instituciones, que sirven de espejo a otras más periféricas.

Antes de iniciar la exposición de los datos, queremos hacer hincapié en la belleza sorprendente y envolvente del primer espacio, el "Área introductoria" como la denomina Carretero (2012), en la que la persona visitante podría pasar más de una hora disfrutando de la presentación audiovisual con proyecciones multipantalla y del interactivo titulado "España, un gran yacimiento". En una de las pequeñas pantallas aparece la Dama de Baza ilustrando una especialidad de la Arqueología, la "Arqueología de Género". Un muy buen recibimiento para nuestras intenciones.

\section{Análisis de las representaciones de mujeres en el nuevo MAN: las salas de Prehistoria y Protohistoria}

\begin{tabular}{|c|c|c|c|c|}
\hline & $\begin{array}{l}\text { PALEO- } \\
\text { LÍTICO }\end{array}$ & $\begin{array}{l}\text { NEOL.Y } \\
\text { BRONCE }\end{array}$ & $\begin{array}{c}\text { PROTOHIS- } \\
\text { TORIA }\end{array}$ & TOTAL \\
\hline ESCENAS & 20 & 15 & 28 & 63 \\
\hline FIGURAS & 145 & 252 & 335 & 732 \\
\hline HOMBRES & 110 & 198 & 240 & 548 \\
\hline MUJERES & $\begin{array}{c}35 \\
(24,1 \%)\end{array}$ & $\begin{array}{c}54 \\
(21,4 \%)\end{array}$ & $\begin{array}{c}95 \\
(28,3 \%)\end{array}$ & $\begin{array}{c}184 \\
(25,1 \%)\end{array}$ \\
\hline
\end{tabular}

En este cuadro puede observarse cómo la cantidad de escenas es realmente alta, menor en la sección de Neolítico y Bronce y mayor en la de Protohistoria. La media de personas representadas en cada escena es de 12 , lo que significa que muchas de ellas tienen carácter multitudinario. Más o menos el $70 \%$ de las figuras son dibujos, por lo general de muy buena calidad; el resto son escenas procedentes de videos, contextos en los que parece haber habido cierto esfuerzo por no dejar claro el género de los personajes. Aun así hemos podido distinguir el sexo nada menos que en 732 figuras, de las que el $25,1 \%$ son mujeres. Se trata de un porcentaje muy similar al encontrado en el Museo de la Evolución Humana en Burgos, situado en la zona alta de nuestro estudio general. 


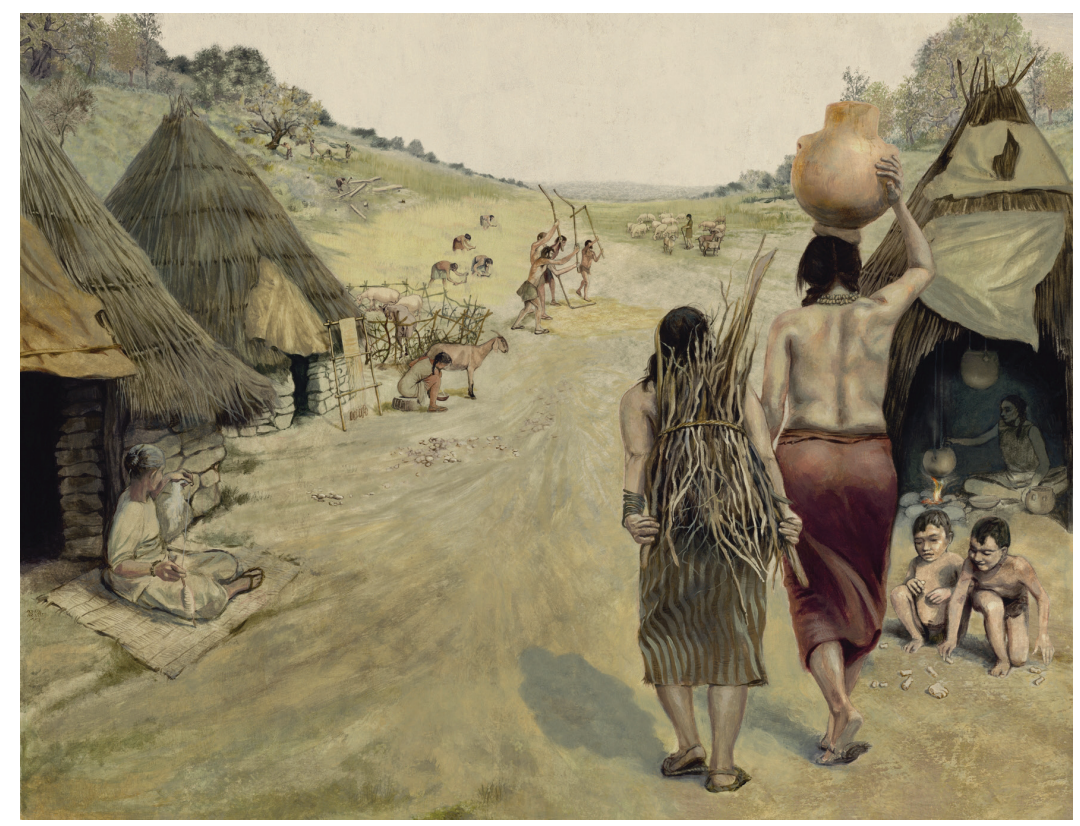

Fig. 1. Mujeres caminando en la sala de Neolítico/bronce (Fotografía: Archivo MAN).

Es muy interesante comprobar, en el conjunto, las posiciones en las que aparecen las mujeres, con una gran mayoría en pie $(66,3 \%)$ (Fig. 1), un $20,2 \%$ sentadas, $7 \%$ agachadas o inclinadas y un $6,5 \%$ de rodillas, de las cuales un tercio presentan tan solo una rodilla en tierra.

En cuanto a los trabajos que desempeñan las mujeres, llama la atención su participación en tareas "propias" de hombres que exigen fuerza física (Fig. 2). Pero la mayoría de ellas caminan $(28,3 \%)$, van en procesión o se dirigen a algún lugar, de espaldas o de frente, cargadas o no. En un porcentaje similar $(25,6 \%)$ las mujeres están: bien de pie, bien sentadas, pero no realizan tareas o desempeñan roles claros, simplemente están ahí.

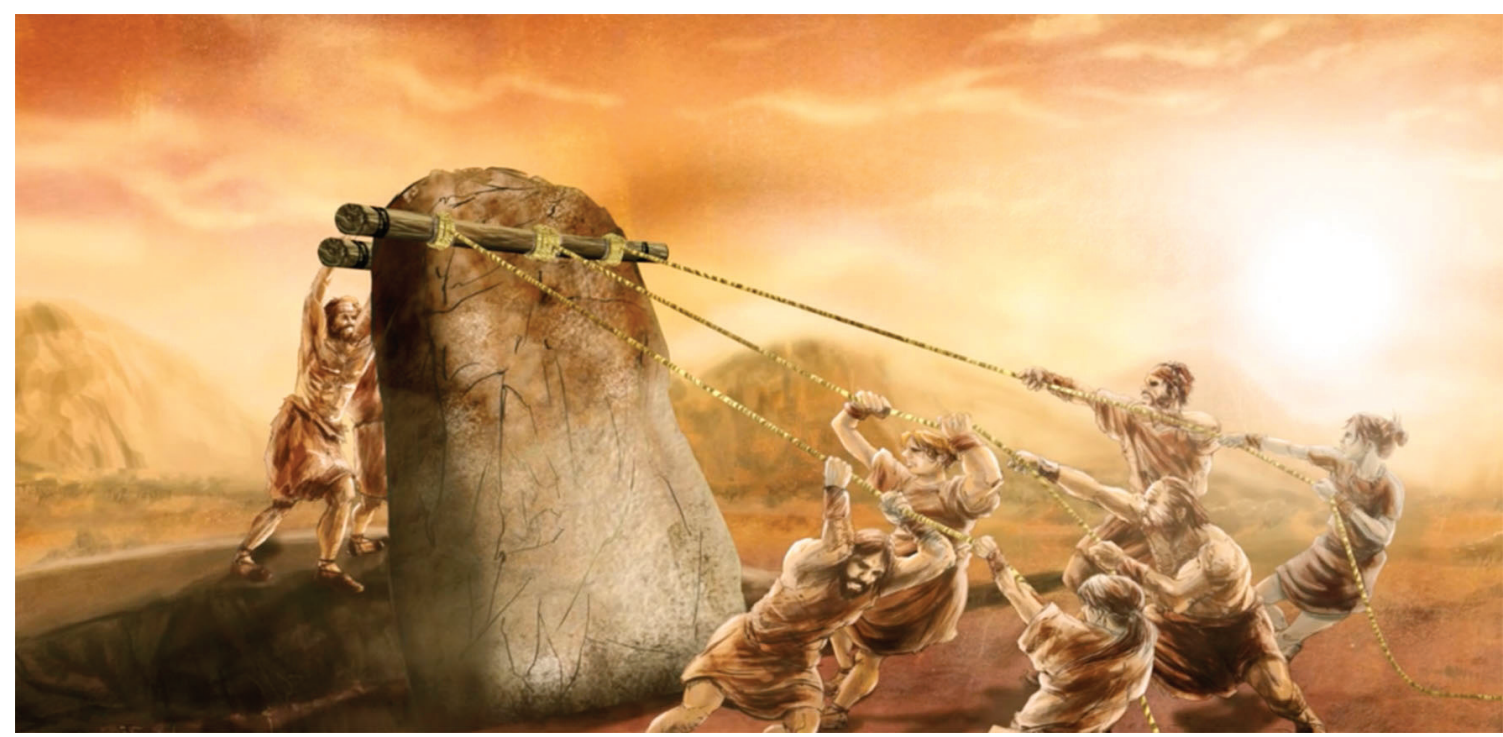

Fig. 2. Una mujer en un trabajo de construcción que requiere gran fuerza física (Fotografía: Archivo MAN). 


\begin{tabular}{|l|c|c|c|c|}
\hline $\begin{array}{l}\text { POSICIO- } \\
\text { NES }\end{array}$ & $\begin{array}{c}\text { PALEOLÍ- } \\
\text { TICO }\end{array}$ & $\begin{array}{c}\text { NEOL. Y } \\
\text { BRONCE }\end{array}$ & $\begin{array}{c}\text { PROTO- } \\
\text { HIST. }\end{array}$ & TOTALES \\
\hline EN PIE & 16 & 36 & 70 & $122(66,3 \%)$ \\
\hline $\begin{array}{l}\text { SENTA- } \\
\text { DAS }\end{array}$ & 12 & 7 & 18 & $37(20,2 \%)$ \\
\hline $\begin{array}{l}\text { AGACHA- } \\
\text { DAS }\end{array}$ & 6 & 4 & 4 & $5(2,7 \%)$ \\
\hline $\begin{array}{l}\text { DE RODI- } \\
\text { LLAS }\end{array}$ & 2 & 7 & 3 & $12(6,5 \%)$ \\
\hline TOTALES & 35 & 54 & 95 & 184 \\
\hline
\end{tabular}

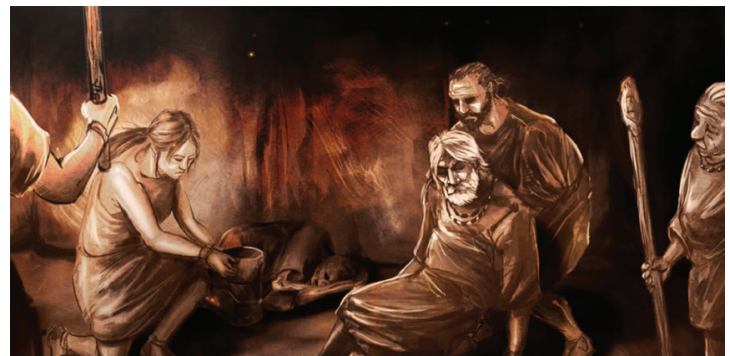

Fig. 3. En el nuevo MAN abundan las mujeres en espacios funerarios (Fotografía: Archivo MAN).

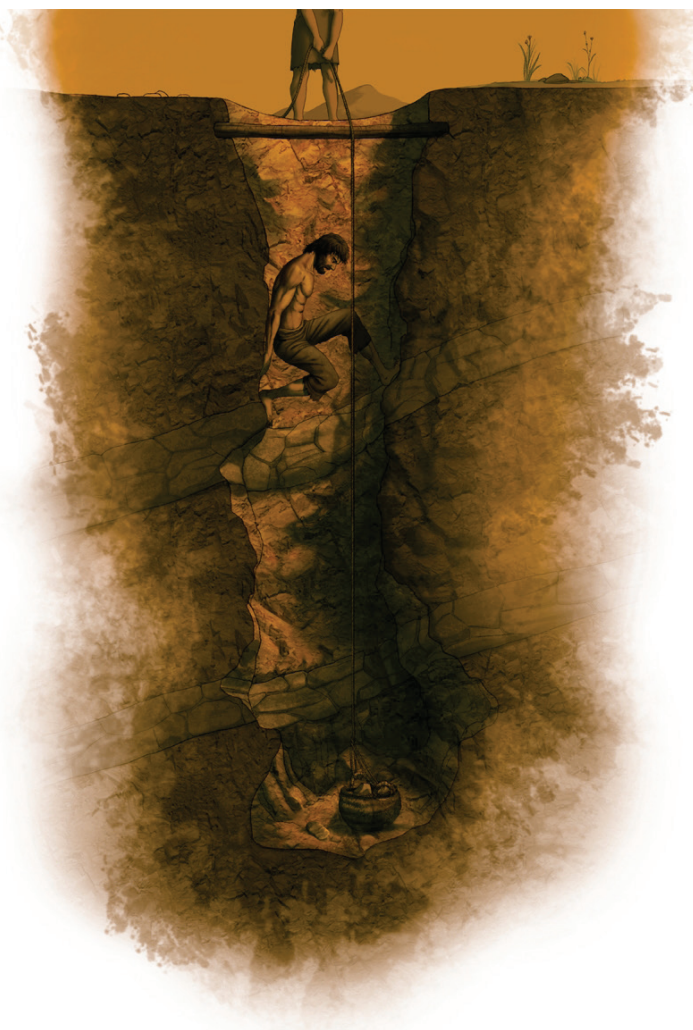

Fig. 4. Un mujer (en realidad, media) en un contexto de minería (Fotografía: Archivo MAN).
Sobresale también la importante cantidad de mujeres que participan en los funerales (Fig. 3), escena esta última muy repetida en este nuevo MAN -tal vez un museo de entierros y procesiones-. Y aunque el número es pequeño, aparecen mujeres trabajando en ámbitos tradicionalmente masculinos, como la minería (Fig. 4), la construcción o la caza, lo que sin duda ha supuesto un esfuerzo consciente por parte de las personas responsables del diseño. 


\section{Conclusiones: Caminando hacia un nuevo mundo}

Es evidente que al intentar introducir los resultados de nuestras investigaciones en el ciclo de conocimiento de la historia, no tenemos más remedio que incluir a los grupos humanos, a las sociedades del pasado. Es entonces cuando nos damos cuenta de que entre el apurado y sofisticado conocimiento de las medidas, las composiciones químicas y los procesos técnicos, y la gente que estaba por detrás de todo ello, existe un abismo sobre el que se ha escrito más bien poco (ver Hernando 2002).

Por lo que respecta, en concreto, al tema que nos ocupa, el papel de las mujeres en las sociedades del pasado, ¿cuáles son los caminos establecidos por la ciencia arqueológica para averiguarlo? O, con otra formulación, ¿le ha preocupado a la ciencia arqueológica establecer caminos para averiguarlo? Las respuestas no son positivas. Y lo mismo se puede decir ante cualquier otra pre-

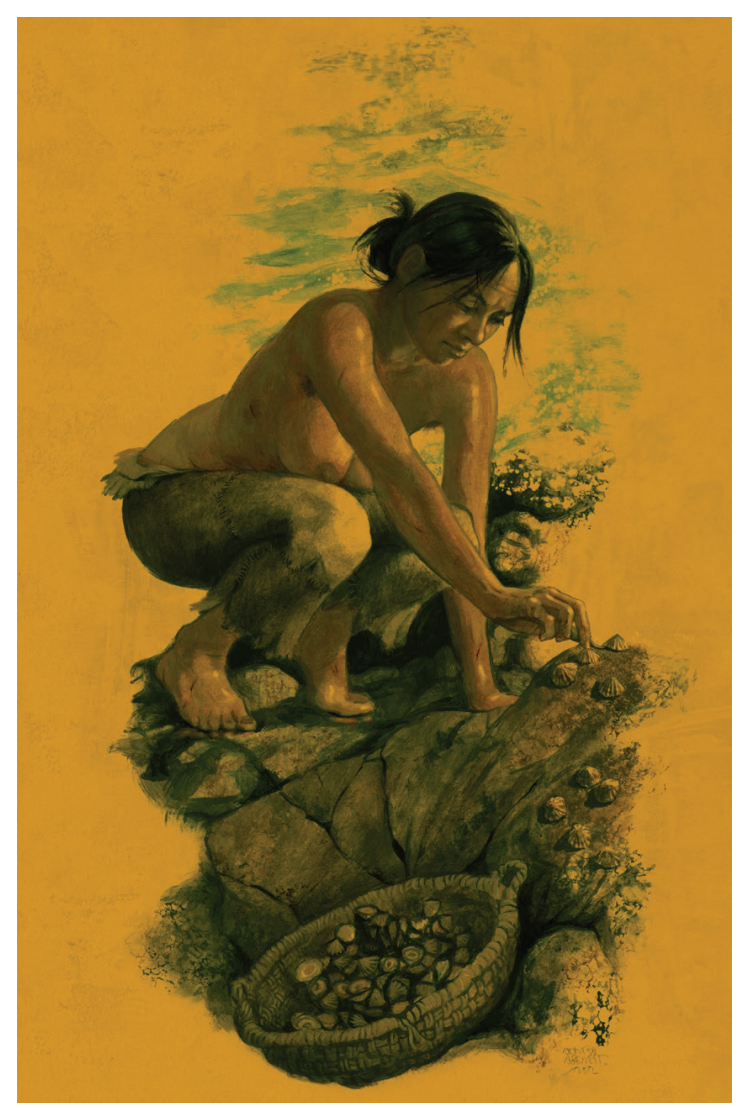

Fig. 5. Una mujer mariscando (Fotografía: Archivo MAN). gunta puramente social, como por ejemplo si las personas de cierta edad trabajaban, si las criaturas eran cuidadas por sus propias madres o por grupos de hombres/mujeres, cuáles eran los tabúes, si es que los había, en torno a la menstruación o qué importancia alcanzó, en determinada sociedad, la fabricación de cerámica o la recogida de leña.

Las nuevas instalaciones del MAN, además de suponer una decidida apuesta por la calidad, la belleza y la inteligencia al servicio de la moderna museografía, demuestran haber tenido en cuenta la necesidad de la representación de las mujeres del pasado en actitudes activas y cooperativas. Por supuesto que hay mujeres cuidando bebés, con criaturas en brazos y en espacios interiores, y aunque el porcentaje total no alcance el $50 \%$ de nuestra utopía, el nuevo MAN constituye un importante paso adelante en esta pequeña historia de la representación de las mujeres en los museos arqueológicos que estamos siguiendo. Por primera vez en nuestros trabajos vemos mujeres en ambientes de minería, las vemos por supuesto en recolección (Fig. 5), pero también en caza, y además se insiste en su presencia en contextos constructivos que exigen fuerza, o en ámbitos directivos que exigen inteligencia y suponen respeto (Fig. 6). Además, de un total de 63 escenas analizadas, tan sólo 13 (un 20,6 \%) presentan hombres exclusivamente: tres escenas de caza en la sala de Paleolítico, otras tres -dos de ellas de minería- en la de Neolítico y Bronce, y siete, diversas, en la de Protohistoria. Esto quiere decir que, si comparamos estas salas del nuevo MAN con los otros museos estudiados, aquí hay mujeres casi por todas partes.

$\mathrm{Y}$ aunque no haya formado parte de nuestro estudio, queremos resaltar el sistema de presentación de las colecciones de Grecia, hecha a mayor gloria de la autoridad masculina, traducción del pensamiento griego androcéntrico. En ella, la oposición hombre/mujer resulta tan exagerada que se convierte en una visibilización material de los orígenes del que contribuye a hacer más fácil su reconstrucción y su comprensión.

Es evidente que aún queda por hacer y que seguiremos insistiendo en esta demanda de conciencia feminista; la sociedad actual necesita recibir mensajes de equilibrio y cooperación que consigan alejarla de esa idea tan generalizada y tan peligrosa de que la invisibilidad, la inferioridad y la escasa importancia de las mujeres y de sus trabajos ha sido siempre igual, desde el principio de los tiempos. Los museos arqueológicos, 


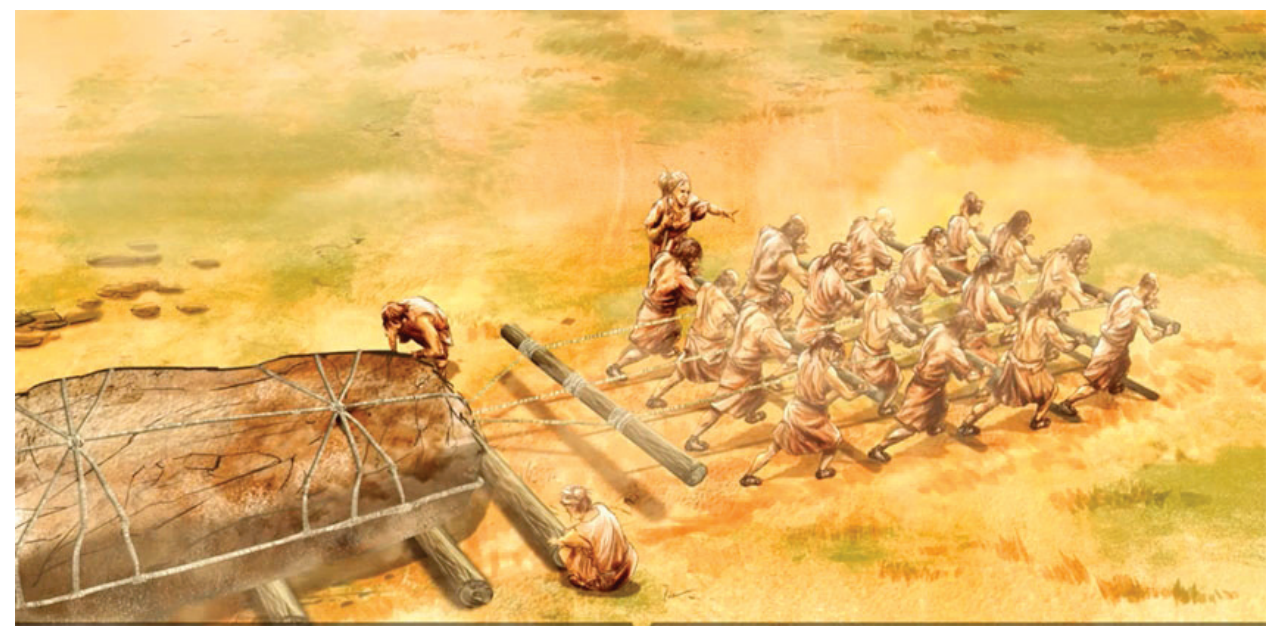

Fig. 6. Una mujer dirigiendo un trabajo colectivo (Fotografía: Archivo MAN).

explicando el pasado con la intención de hacer comprender el presente y al mismo tiempo dotarlo de raíces, se enfrentan al reto de contribuir a la construcción de un mundo nuevo, un pasado distinto y cercano que nos presente, a las mujeres, en igualdad de importancia y de respeto frente a los hombres, con independencia de poder o no responder a la pregunta de ¿cuál fue la realidad? El nuevo MAN ha sabido asumir que esa respuesta cambia con los tiempos, y que ahora, en este tiempo, toca dar este paso adelante, en positivo, que aquí hemos presentado.

\section{Notas}

1. Agradecemos su valiosa ayuda a Elena Galán, dedicada alumna del Grado en Arqueología.

\section{REFERENCIAS BibLIOGRÁficas}

Carretero, A (2012): La renovación del Museo Arqueológico Nacional 2008-2012, Madrid. $8^{\circ}$ Encuentro Internacional Actualidad en Museografía, ICOM España: 121-146.

DíAz-Andreu, M. (2005): Género y Arqueología: una nueva síntesis. Arqueología y Género. (M. Sánchez Romero, ed.), Universidad de Granada: 13-51.

Hernando, A. (2002): Arqueología de la identidad. Akal, Madrid.

Hornos Mata, F.; Risquez Cuenca, C. (2000): Paseando por un museo y buscando el lugar de la mujer. Arqueología Espacial 22: 175-186.

Hornos Mata, F.; Risquez Cuenca, C. (2005): Representación en la actualidad: las mujeres en los museos. Arqueología y Género. (M. Sánchez Romero, ed.), Universidad de Granada: 479-490.

Querol, Ma . A. (2000): El espacio de la mujer en el discurso sobre el origen de la humanidad. Arqueología Espacial 22: 161-173.

Querol, Ma ${ }^{\mathrm{a}}$. A. (2001): Adán y Darwin. Editorial Síntesis, Serie Arqueología Prehistórica no ${ }^{5}$. Madrid.

Querol, Ma . A. (2003): Eva la diferente. X Coloquio Internacional de la Asociación Española de Investigación de Historia de las Mujeres: Representación, Construcción e Interpretación de la imagen visual de la mujer. Editado por AEIHM e Instituto de Cultura y Tecnología "Miguel de Unamuno": 103- 118.

Querol, $\mathrm{M}^{\mathrm{a}}$ A. (2005): Las mujeres en los relatos sobre los orígenes de la humanidad. T. I.: Historia de las mujeres en España y América latina. Vol. 1: de la Prehistoria a la Edad Media (I. Morant, dir.), Cátedra, Madrid: 27- 77. 
Querol, Ma . A. (2006): Los discursos actualistas en las representaciones de la Arqueología prehistórica: una visión feminista. III Congreso Internacional de Musealización de Yacimientos Arqueológicos, Zaragoza. pp. 36-44.

Querol, Ma . A.; Hornos MatA, F. (2011): La representación de las mujeres en los modernos museos arqueológicos: estudio de cinco casos. Revista Atlántica-Mediterránea 13:135-156.

Querol, Ma . A.; Triviño, C. (2004): La mujer en "El Origen del Hombre". Ediciones Bellaterra, serie Arqueología.

Soler Mayor, B. (2008): De la investigación a la difusión: el museo como vehículo de mediación. Arenal, revista de historia de las mujeres 15 (1): 179-194. 